University of Warwick institutional repository: http://go.warwick.ac.uk/wrap This paper is made available online in accordance with publisher policies. Please scroll down to view the document itself. Please refer to the repository record for this item and our policy information available from the repository home page for further information.

To see the final version of this paper please visit the publisher's website. Access to the published version may require a subscription.

Author(s): Angela Bolton, Christopher Pole and Phillip Mizen Article Title: Picture This: Researching Child Workers

Year of publication: 2001

Link to published version: http://dx.doi.org/

10.1017/S0038038501000244

Publisher statement: None 


\title{
Picture This: Researching Child Workers
}

\author{
Angela Bolton, Christopher Pole and Phillip Mizen \\ Barnardos \\ Department of Sociology \\ University of Leicester \\ Department of Sociology \\ University of Warwick
}

\begin{abstract}
Visual methods such as photography are under-used in the active process of sociological research. As rare as visual methods are, it is even rarer for the resultant images to be made by rather than of research participants. Primarily, the paper explores the challenges and contradictions of using photography within a multi-method approach. We consider processes for analysing visual data, different ways of utilising visual methods in sociological research, and the use of primary and secondary data, or, simple illustration versus active visual exploration of the social. The question of triangulation of visual data against text and testimony versus a stand-alone approach is explored in depth.
\end{abstract}

KEYWORDS child employment, child labour, childhood, multi-strategy research, photography, visual sociology.

A set of photographs shows the various sites and scenes of activity in a small branch of a burger bar. We see: a group of children having a party, shots of the counter, a teenage employee serving a drink, the stock-room, the kitchen, the staff-room.

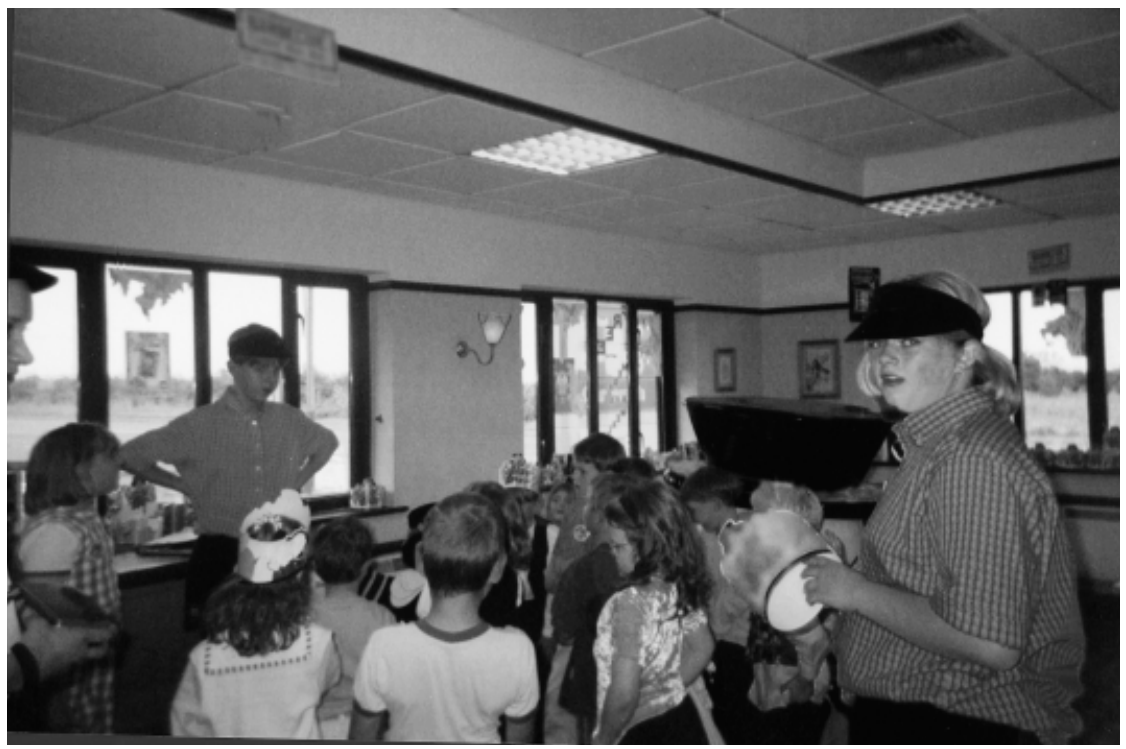




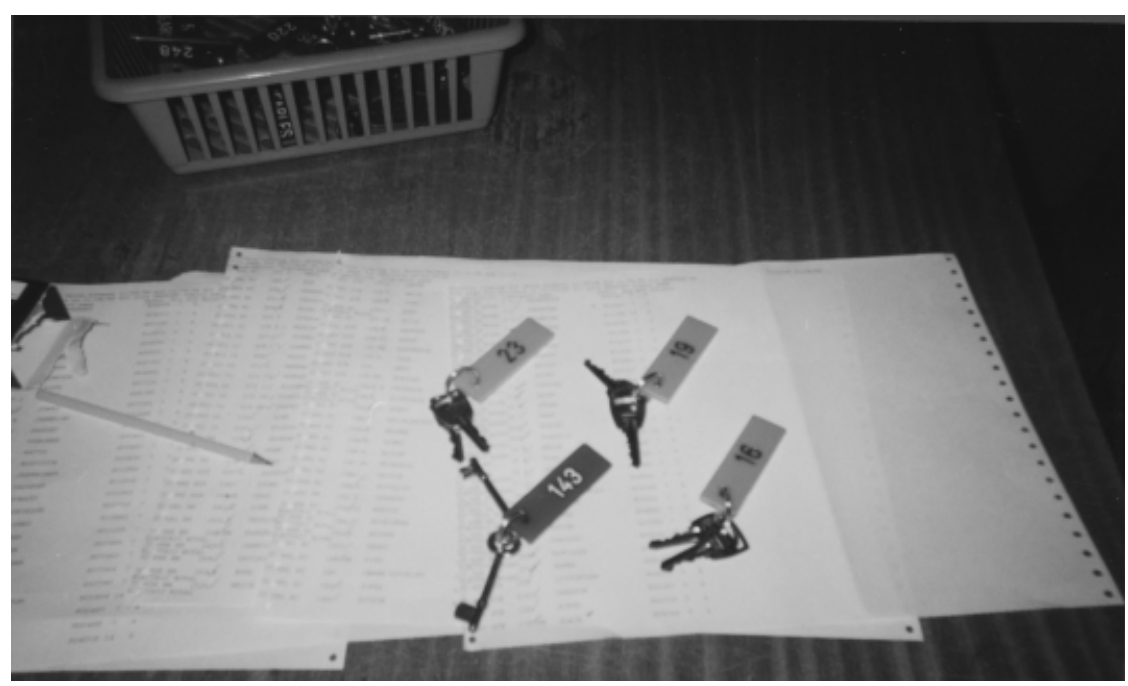

Other pictures in the same set of prints show a seaside caravan site: a welcome sign at the gate; keys laid out on a desk; stacks of sheets in a linen cupboard; a 'milkfloat' with 'Housekeeping Department' emblazoned across it. Back in the burger bar two teenagers dressed in uniform oversee the children's party, a group of younger children are looking at and apparently listening to a teenage boy who stands at the front. He appears to be in charge. The technical quality of these photographs is variable, some are blurred, others obscured by thumbs, none come anywhere near a professional standard but this is hardly surprising given that the photographer has viewed and recorded aspects of her working life through a cheap, single-use, disposable camera with a fixed focus lens. Lindsey, the photographer, is 14 . She attends a British secondary school full-time but also holds down two part-time jobs. One, in the 'Housekeeping Department' at a caravan site, she has held since she was 12. More recently she has worked at the burger chain alongside Nathan, a 15-year-old boy from the same school, the boy who appears to be in charge in the party photo. In his photo diary, in which he has chosen and written about six of his own photographs Nathan tells us 'I am now head of parties'. As Lindsey's photograph seemed to indicate, Nathan was indeed in charge.

These photographs serve as a useful introduction to this paper, the focus of which is to engage with debates about the role of photography in sociological research. Increased interest in the use of the visual in sociology raises important questions about the capacity of photography and other visual media, to act as more than mere illustrations of sociological endeavour. Arguments that Visual Sociology has a capacity to go beyond representation, attribute to it a role in broader socio- 


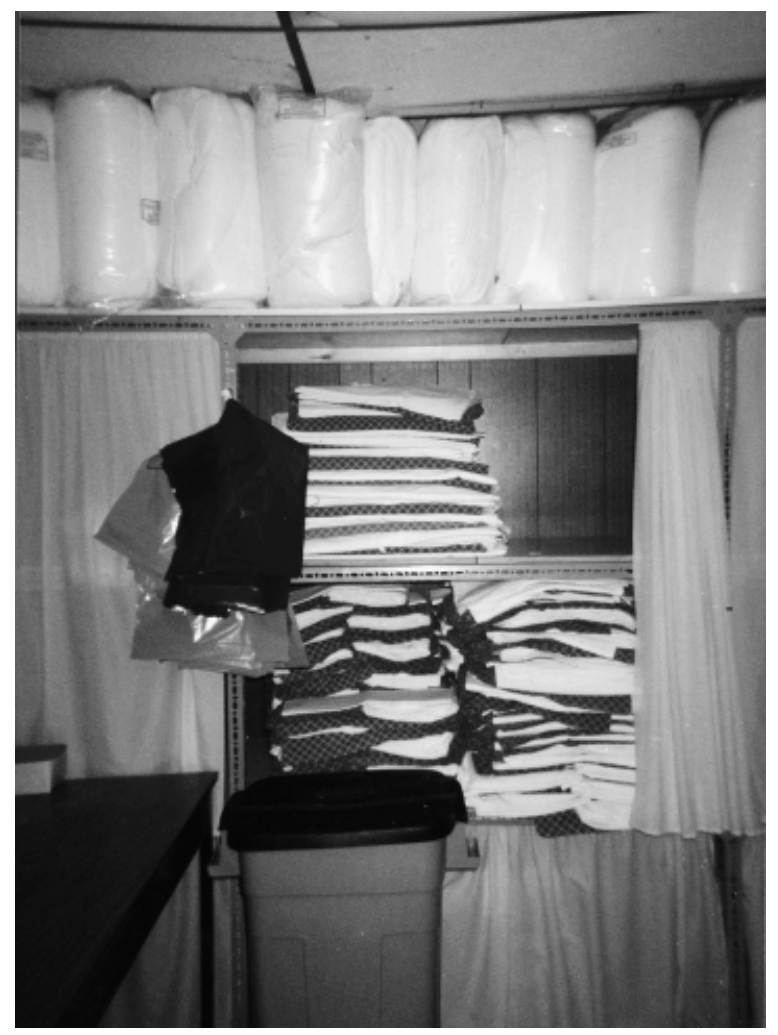

logical enquiry, where it can create rather than merely collect distinctive data. As such, we argue that this conceptual differentiation between visual sociology and Visual Sociology imbues the latter with analytical value not present in other research methods. Moreover, it offers the sociologist an opportunity to gain not just more but different insights into social phenomena, which research methods relying on oral, aural or written data cannot provide.

Using examples from our research into the working and economic lives of 11 to 16 year olds (Mizen, Bolton and Pole 1999), which involved research participants taking, or perhaps more accurately making, photographs of the part-time jobs alongside more conventional research methods of interview, focus groups and written diaries (Pole, Mizen and Bolton 1999), the intention of this paper is to explore the possibilities and constraints which inform the capacity of Visual Sociology to make a distinctive contribution to understanding aspects of social life.

Recent trends and debates about Visual Sociology raise important methodological questions about the status and treatment of different sources of data relative to one another and highlight debates about power and the conduct of research, 
about ethics and the generation and nature of knowledge. Throughout this paper we draw upon our own research with working children to engage with these and other issues. In the first section we consider very different ways in which visual approaches to sociological research have been used to open up some of the possibilities of this under-used medium. Next, we reflect upon the use of photographic methods in pursuit of an understanding of child employment and in conducting research with children as active participants, not passive subjects. To situate the broad themes of the paper within our own research practice we look at issues of power, selectivity, making sense of data and macro versus micro or 'the big picture', considering both content and form of the visual data. In the final section we explore both accord and disjunction between visual and other forms of data and assess the use of photography as a tool in the development of our own sociological understanding of child employment.

\section{Visual sociology: discipline or method?}

Visual images imbue modern society with potent and persuasive means to convey information, evoke mood or sell products. Rarely do we get what we see, so much so that, as viewers, we approach visual imagery with something of a jaundiced eye. Are we seeing a fair representation of reality in the visual image, indeed in the photographs described above? We know that photographers can be highly selective in constructing their subject and so as sociologists, as consumers, as viewers we rarely respond to images as simple truth. We are used to visual material being shot through with a hidden or not-so-hidden agenda - having an ulterior purpose.

Within sociology and social research the separation of talk or text and visual image remains striking. Most sociological texts or monographs will contain only one visual image. We are exhorted not to judge a book by its cover, and yet here it is that we generally find the only use of visual material! Paradoxically it may be the very power and ready accessibility of visual images, the apparent transparency of their message, which leads us to dismiss their value as a serious source of data and sociological understanding. Increasingly well-versed in reading and de-coding pictures or photographs, in stepping back from this apparently simple route to understanding, we may suspect the veracity of the academic message or claim to knowledge which comes in this medium, we look for conventional, textual confirmation. At best in sociological research we tend to 'read' visual material as ancillary to the text, supportive or illustrative of the real message, at worst we dismiss it as a suspect or lazy representation of reality. Rarely is it used in such a way as to 'speak for itself' or in a way which recognises its capacity to bring a distinctive contribution to sociological enquiry.

Despite this, the use of visual methods in sociological research is growing with dedicated publications and increasing interest in the potential for visual methods 
not only to unlock access to elusive data but also to contribute to sociological understanding through the use of visual techniques (Harper 1998). That more sociologists seem happy to include visual methods in their research design suggests that visual sociology may be moving away from its traditional supporting role to one in which Visual Sociology is recognised as for its own heuristic and analytical merit.

The visual exploration and representation of sociological problems and issues is posed here and by others as an under-used approach, largely appropriated by semiotics yet with a much broader application, and, we would argue having a potential affinity with a more realist-materialist perspective. The analysis of popular visual culture now underpins some strands of sociology as a discipline. Feldman (1995) claims semiotics, the divining of social meanings through the signification of cultural symbols and artefacts, as an epistemological approach in and of itself. This strand of sociology often has the visual iconography of the everyday at its centre. However, our argument, which accords with that of Collier (1967) might be dismissed by post-modern thinkers and semioticians as a naïve realist approach, in its claim that the collection and analysis of extant visual material is to be differentiated from the research-active doing or making of sociology through visual means. Methodologically we wish to look further at Harper's (1998) claim of a natural marriage between ethnography and visual methods.

In response to these divergent aspects of the visual in sociology two key questions arise for us. First, is it to be the case that the doing of visual sociology will continue to be limited largely as Becker (1974) and later Banks (1998) have noted to the making of ethnographic films or can it be drawn into mainstream sociological praxis? Secondly, can visual sociology be rescued from the semioticians to take a place in a critical but realist or materialist approach to the exploration of social problems, in our case the shape and meaning of child employment in social, economic and family context?

The first issue to consider is whether all forms of visual material can be viewed as sociological data. Are we to think of collections of family photographs in the sense of 'documents of life' (Plummer 1983), another form of secondary data to add to the bigger picture, one more component of a thorough approach to documentary research? Or should we become more alert to the potential of visual methods, specifically photography, as a potent means to access neglected forms of primary data? Most simply the sociological analysis of visual material can be divided along these lines into the analysis and interrogation of existing visual material and the creation of new primary data. Collier (1967, p. x, cited in Harper, 1998:27) makes a finer distinction within the latter to stress the role of visual techniques in the active process of investigation. He distinguishes between the use of visual material to merely represent, illuminate or document known social processes, events and meanings through the familiar devices of the front-cover illustration or sporadic intext photograph on the one hand and on the other, the active research process whose 
raison d'être is the development of sociological understanding through visual techniques and the generation of primary visual data sources.

Those who seek to delineate Visual Sociology as a discipline tend to accord with the latter to see their distinctive contribution as the a priori use of visual techniques for the development of sociological understanding. Although the resultant images may subsequently be compared with archival material for a 'then and now' approach or set alongside other data sources, the important distinction is that the images have been created as part of a sociological investigation; the visual element has been part of an active process of seeking and hopefully reaching understanding, rather than merely illustrating findings arrived at by other means. Consequently, the sociologist who takes a few photographs at the end of their research to illustrate and support what they have learned by non-visual methods is generally to be disqualified. They have not by this definition engaged in Visual Sociology.

\section{Records of culture or records about culture?}

The focus on an active process does not generally extend as far as the participants, it is not they who are to be active. The emphasis on writing for and about the researcher as image-maker rather than image-gatherer tends simultaneously to relegate the participant to the other side of the lens bringing into play Worth's (1980) distinction between visual records of culture and records about culture. Those made by participants detailing their own lives are records of culture. Therefore much of what is presented as visual sociology becomes a record about culture.

Visual records of culture are to be found in open-access television, and the BBC's Video Nation series. In these short video diaries some of which are akin to poems, reminiscences, lectures or moral exhortations, the visual element privileges the 'talking head' with the rest of the visual world, the visual detritus and detail of everyday life which may confirm, contradict, expand or situate the spoken accounts squeezed to the sides. The moving picture is not the same as the frozen still, though arguably more 'real' and with the rapid development and decreasing cost of multimedia technology enabling the transfer and transformation of one media into another perhaps soon to be no less accessible to the sociologist. Video lends itself to diary work in private time and space or by empowered individuals in public. Hubbard's (1991) powerful project 'Shooting Back: A Photographic View of Life by Homeless Children', attempts both, working with a marginalised group and using empowering methods. Homeless children, dispossessed and powerless are allowed for once to describe their environment rather than their environment defining them. But in most visual sociology the researcher remains the central, powerful, defining presence.

In inviting the participants in our study of working children to take photographs 
of their part-time jobs and their working lives more generally, our intention was to gain access to a visual record of their culture rather than about their culture. In this sense, the fact that they were behind the lens becomes at least as significant, if not more significant, as what is in front of it. Their choice of what to include in the frame and what to leave out provides us as the researchers not merely with data as illustration, but with a form of data which has been selected and subject to a process of analysis for its significance to the culture of the research participants. With this reading of our photographs, the distinction between those who are researching and those who are being researched becomes blurred.

\section{Ways of seeing: different strands of Visual Sociology}

What then are the implications of the distinction between the collection of visual data for the purposes of sociological analysis (Visual Sociology) rather than the illustration of established or even emergent findings (visual sociology)? By this definition, Visual Sociology has something like a 25-year history, linked to a body of work drawn together by key figures such as Howard Becker. The links with anthropology, of course, root visual sociology in a long established research tradition most popularly exemplified in Balinese Character, Mead and Bateson's extensive and partly-visual cataloguing of a culture unfamiliar to Western eyes (see Harper 1998). Visual Sociology has since developed in several directions. Becker (1998) has explored the blurred boundaries between art photography, photo-journalism and social investigation, challenging us to discern where one melds into the other. But the artistry of the image is not generally the primary concern of the sociologist. What then is the usual role of the visual in sociological research? Some augments community or topographical surveys with visual material, whilst Harper (1998) argues that there exists a natural marriage between visual sociology and ethnography. A third strand records social change over time, as distinct from the one-off recording of social phenomena. Again this may be at a community, topographical or biographical level (see Davis 1993 and Rieger 1996 for two review articles).

If Visual Sociology, as an active and arguably distinct discipline, has a relatively short history, a longer-lived approach has been the sociological analysis of the genesis and role of the visual arts and aesthetic movements and the relationship between aesthetic values, epistemology and the evolution of philosophical thought. Berger's 'Ways of Seeing' (1972) is the classic in the discipline. Elizabeth Chaplin's (1994) work both continues and goes beyond this tradition to catalogue her own artistic endeavour. She reaches beyond the conventional boundary of art history to update us on the visual metaphors of our times; both those embedded in contemporary artistic outpourings and those created through visual material, which has been newly and explicitly made for sociological purposes.

Looking at the different strands in greater detail, Harper's claim of an affinity 
between the aims of ethnography and the data which may be gathered by visual methods is tempered by recognition that its application has been limited to date outside of ethnographic film (Worth and Adair 1972). Payne (1993) also identifies this limitation of the visual in ethnographic community studies, most classic community studies failing to explore the visual in their urban topography, allowing their attempts to be constrained by language when photographs or diagrams (see Cohen 1997 for use of the latter) of the community setting under study would have set the context, located the social interaction in the surroundings which shape, constrain or enable everyday life (Payne 1993). Amongst those who have crossed over into visual methods, ethnography's traditional preoccupation with the marginalised and powerless would seem to continue. Some have used photography to enter into and work amongst what is arguably a community of interest, though often a community characterised by the disinterest of mainstream society: homeless men on the move in the United States, the 'hoboes' of the 1930s rediscovered for the 1980s (Harper 1982).

A further strand is the overtly campaign-oriented photography, which has grown out of political protest or action, using the methods of the photo-journalism of the 1930 or repeating earlier photographic social and topographical surveys. In the work of the 'serious photojournalists' of the early twentieth century Becker acknowledges a collective and sociological debt to those who 'made it their business to record the poverty and hard times of Depression America, their work very much informed by social science theories of various kinds' (1974:3). Most famously the Farm Security Administration organised the visual documentation of migration during the Great Depression and the dogged survival of those who remained in the dustbowl of the American Midwest (Rieger 1996). Later collectives of the 1970s and 1980s in the United States include 'The Atomic Photographers Guild' and 'The New Topographers', the eponymous titles conveying their shared 'common framework of revisionist principles' (Davis 1993:57).

Both photo-journalistic exposés and topographical surveys in the United States inspired later photographers to revisit earlier sites and subjects (Rieger 1982; Klett et al. 1984). Arguably re-photography is a methodological approach rather than a strand of Visual Sociology, but one worth recounting for its elongated use of timeseries photography. This approach is more usually associated with the breaking down of change or movement into its constituent parts - the process of walking, rendered as a series of stills; the speeding up of still or filmic images of infinitesimal processes or constant movement until patterns, ebbs and flows emerge from the detail, for example, the passage of human and vehicular traffic through a city (see Reggio's film Koyaanasquatsi, made in 1983). In the process of photographing social change the time lapse may be a century or more, or half a life-time as photographers return to the scene or subject of an earlier photographer's work to record and analyse the impact of social processes on towns, land, buildings or individuals during the time which has lapsed. In Rieger's (1996) case the time-lapse is less. He returns fifteen 
years on to repeat his original community studies of 1970, seeking out the same position from which to record social or community change in its minutiae, change of building use, physical decay, the closure of businesses, increase in traffic. In one of the most striking (perhaps because it is biographical) examples of the re-photography approach, Ganzel (1984) traced the subject of Dorothea Lange's iconic Depression portrait of a 'migrant mother' and her children in a labourers' camp taken in 1936. Florence Thompson and family abandoned her native Midwest and travelled to the fields of California, where they eked out a survival as casual farm labourers. Thompson came to represent the impact of the Great Depression as a result of Lange's portrait, becoming 'probably the single most famous image' (Rieger 1996:28). Her prematurely aged face looks off to the side of the camera, two of her daughters hide their faces in her neck. Forty years later in Ganzel's 1979 portrait, the former migrant mother, now nearly 8o, sits in the garden of her California home, surrounded by her grown-up daughters who smile out at the camera. Superficially, it can be read, misinterpreted perhaps, as a photograph of success, of stability against the odds but her story testifies to the endurance of casual low-paid work and poverty throughout her adult years (Rieger 1996). To equate these examples of re-photography and photo-journalism with issues of culture discussed earlier, then these photographs clearly represent examples about culture rather than of culture.

In some photo-journalism the blurring of the boundary between art and documentary or social commentary is evident. For Davis (1993) Misrach's boundarycrossing images, chosen for their elegiac qualities, document the poisoning and physical destruction of the American Midwest by the Cold War activities of nuclear and bio-chemical testing and conventional bombing practice in the ancient spaces of the Nevada and Utah deserts. Davis (1993:53) describes Misrach's (1992) work as a 'huge mural of forbidden visions ... which dissolves the boundary between documentary and allegory'. In this work an artist's eye and professional photographer's technical proficiency combine to compose the subject matter of ruined landscape, military detritus and the corpses of malformed animals. Few sociologists working through visual means blur the boundaries between art and sociology as fully as Elizabeth Chaplin (1994), who not only sets art history in social context, detailing the transformative possibilities of politically motivated art movements, but who in her own photography takes up the Gramscian challenge of building a counter-culture, counter-pointing in exhibition her own 'feminist' (close-up, intimate, detailed) images against what she characterises as man-made, masculinist images.

More recently, sociological research which employs visual methods seems less challenged by the pressure to produce contextualised, objective, empirical sociological research than exercised by the abandonment of this goal. Harper (1998) critiques the increasing pull in the direction of a post-modern or new ethnography. Here the representational image is no longer measured in terms of objectivity, instead the researcher-photographer is recognised as shaping visual data from their 
world-view, credited with little more than this. Essentially the post-modern challenge to the visual sociologist has been to abandon the pretence of objectivity, to surrender the panopticon gaze and put down the camera. The implication is that visual sociology has merely aped the erstwhile gold-standard of the anthropological approach to document with a cool detachment every aspect of the 'foreign' culture under study. The camera is posed as just one more objectifying tool of colonialist enterprise - now brought home to bear down on the marginalised at close hand.

Whilst the implicit challenge to an unthinking positivism and concealed power relations between observer and observed is to be welcomed, a post-modern ethnographic approach goes much further. Ethnographic standards of both immersion in subject and striving towards wholeness of account are abandoned in recognition of inescapable partiality and partisanship. The danger in our view is that this can lead inexorably back to an introverted celebration of the researcher's view in which participants are largely sidelined, interpretive and analytical attempts halted and a paradoxically empiricist outcome results, where mere surface representation is all.

\section{Shooting the present: young people and work}

Reflecting on the different strands of sociology conducted through visual methods we accepted the challenge to avoid photographic surveillance of the young people with its corollary of paternalistic intervention (Hebdige 1988), but simultaneously we have resisted the relativism of the account and the over-privileging of the text or story implicit in a post-modern reading. Instead, we ask whether photography can play a role in a critical but realist or materialist approach to the exploration of social problems - in this particular instance, the working lives of children. Although we value the emphasis upon context process and multi-method working that emerges clearly in Rieger's work, our aim was not to record social change but to explore a social phenomenon in context, in our case the shape and meaning of child employment in Britain today for the children themselves. To do this we offered a group of seventy young workers an opportunity to make a photographic account of their part-time jobs. As part of a wider, year-long research programme which included interviews, written diary work and focus groups we provided the same young people with disposable cameras and gave a commitment to develop two sets of prints, one for us and one which they could keep.

Our first viewing as a research team of the young people's photographs brought forth an initial disappointment about the tremendous selectivity with which some had approached their subject. There were few action shots. There were few people. We saw workplaces rather than work in action. Several of those who had spent the first half of the year talking in interviews and writing in diaries about busy working environments duly presented us with photographs of empty shops and hairdressing salons at the beginning or end of the working day. 


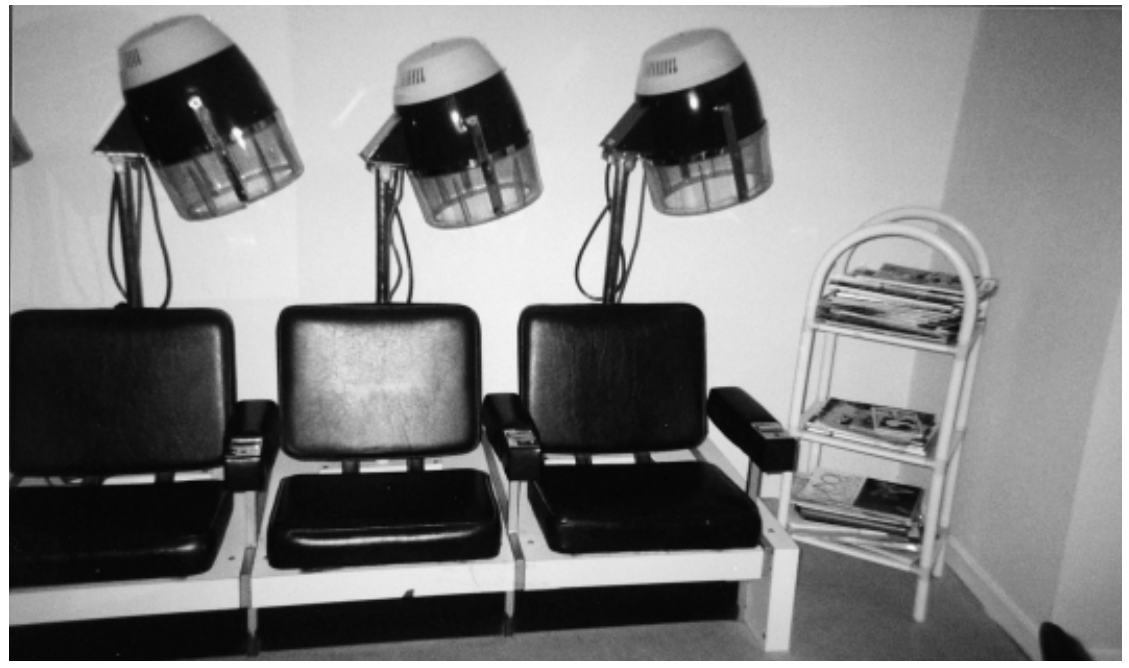

However, in the context of Visual Sociology rather than visual sociology the absence of action and people has significance in the depiction of culture which goes beyond mere representation of the workplace and the experience of work. The photographs, which the young people had produced, brought to life their working environments. They showed in detail not only their workplaces but also their role within them. For example, photographs were taken of stockrooms, of rubbish skips and of toilets. Goffman's notion of front and back stage is evident in these and many

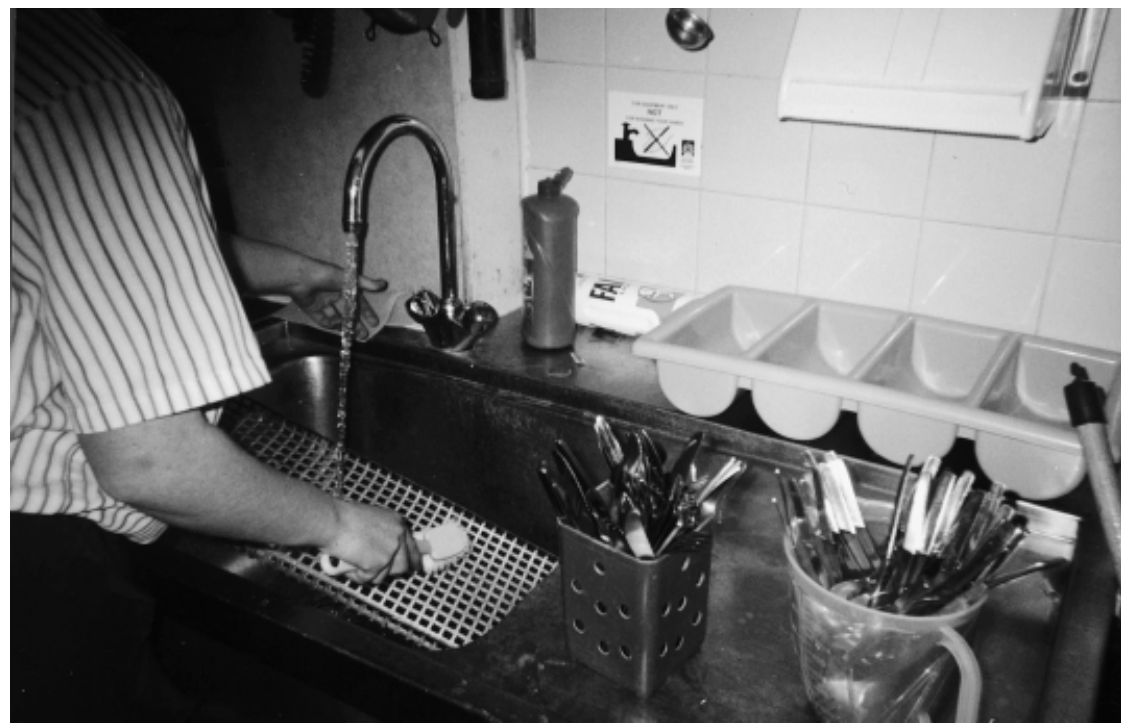


of the photographs. The bundles of towels accumulated in the back room of a hairdresser's contrast with the row of neat hair dryers and styling tables. It is with the dirty towels that the photographer spends much of her working day. The decision to photograph a jumble of chairs taken by a part-time glass collector and general dogsbody at a social club conveys very clearly the reality of the tasks to be carried out as part of the cleaning regime at the club. The pictures convey the reality of the culture of young people's work in a way which the children's written and spoken words do not. They are representations of their work culture, rather than an external researcher/photographers representation about their culture.

\section{Beyond content to form}

At an early stage in the research process issues relating to the form of data as well its content began to emerge, from the absences as well as the positive images recorded. Several aspects are worth exploring. The first is that data generated by this alternative means tended to confirm written and spoken accounts of the content of jobs and the nature of workplaces, showing visual evidence of what we had begun to gather through other means of the social positioning of young people within the workplace. However, through the photographs we have seen places normally unseen by customers and hitherto by ourselves. Some of these elements were clearly new data for us: the material settings of the young people's workplaces: tools; implements; colleagues and the physical plant of their daily or weekly working lives. In addition the form of the pictures indicates relative powerlessness at work. Many photographs were snatched, not only in the inevitable sense of a snapshot or freezeframe of an active scene but also in the making of a secretive record. Of these a significant amount were taken at times when workplaces were not busy, empty even, perhaps when the visual endeavour was safest (in terms of keeping a job) or when it was least disruptive for the young person to take photographs.

Moreover, several young people had earlier decided to opt out of the photographic stage of the research for this very reason, fearing that taking photographs might jeopardise their employment. Others who wanted to do the photography and initially anticipated no problems in taking a camera into work returned cameras with only one or two shots taken, having been asked to stop taking photographs by their employers. In these situations it is the absence of photographs that begins to tell us something about the work experiences of the children by providing an insight into the power relations that govern their employment. It also stimulates a set of questions relating to their employers as to why they might object to the young people taking photographs.

\section{Some analytical strategies}

Prosser and Schwartz approach the analytical processing of visual material through the issue of 'the fallibility and selectivity of the picture maker' (1998:125). 
The researcher's beliefs and standpoint underpin the making of the images and therefore shape the data and must be rendered visible in the analysis. In our case the picture makers are the young people themselves so we can, to an extent, side-step the issue of our own critical distance and are faced instead with their fallibility and selectivity.

In one sense, the young people were our field researchers, working to our research remit as technicians (Finch 1986) in the wider research process. However, to marginalise their role in such a way is to misunderstand both the role and the significance of the photography in our research. Our only instructions to the young people were to take photographs of their work, which showed what it was like to work and what the work meant to them. The photographs were, therefore, composed and selected by the young workers as research participants rather than research objects. They are their interpretation of what is significant to our research focus and in this sense represent initial data analysis. However, issues of significance and analysis do not end with merely selecting or composing and taking the photographs. As the research progressed, issues of the relationship between the photographs and other forms of data became important. As did the way in which the photographs were read and interpreted by us and by the young people. The work of Rieger (1996) and Becker (1998) may help in explaining issues of significance, or meaning, and processes of data analysis here.

Rieger (1996) has advocated the use of visual material in relation to other evidence and as a theoretically situated activity, the researcher having decided the appropriate meanings, signs and symbols to collect as visual evidence of their theoretical target or concern - a purposeful and selective data collection. He takes a somewhat deductive approach, perhaps anathema to the ethnographer but with the caveat that 'the conscientious researcher will document any and all aspects of the phenomenon that could contribute to it sociologically' (1996:42). The researcher/ photographer's understanding of images and captured details will develop with the elicitation of other accounts - spoken, written, statistical, demographic - which are then set alongside the visual account.

Becker (1998) argues that visual sociology is '(almost) all a matter of context', the viewer's response to the work as much as a key to whether a work is deemed sociological or not as the processes undertaken by the researcher/photographer. He advises a methodical approach to the analysis of images, a literal poring over of an image, a naming of everything that is seen with the object of making the taken-forgranted rise to the surface, breaking down the privileging of the central image or object of focus. Context may be spelled-out, or not. Where provided it may be through a written, analytical account of the social phenomenon and processes depicted, the researcher setting the images in theoretical context, spelling out how they have made meaning from the images. Alternatively, a simple presentation of the images allows saturation of the reader/viewer's eye with image after image, 
allowing meaning to filter through and the reader/viewer to extract their own meanings.

Neither Rieger nor Becker falls into the trap of treating images as short-hand or easy-to-read versions of other data sources. For us the starting point of analysis was necessarily the acknowledgement of what was missing alongside that which was present and only then the exploration of what was presented. Arguably some of our analytical strategies derived from our decision to explore the photographs in relation to individual biographies of the young people and from accounts that they wrote of their photographs. However, these have to be seen against our naïve readings of the photographs as stand alone documents and the emerging themes as we looked to understand individual accounts more fully and to understand the patterns and forms which emerged as the project progressed with various sources of data.

\section{Missing the bigger picture?}

Many of the tasks and duties described in interviews with the young people and in the diaries which they kept appeared in photographs: cleaning; carrying and serving refreshments for a sports team; washing up; neutralising perms; feeding animals; serving customers. However, comparison of different data sources also suggested to us that there were significant omissions from the photographs. Reading what was and what was not in the photographs in the context of what we knew, or thought we knew from other sources, became important.

For example, John, 12, works on his father's sheep farm. He selected six of his photographs to write about, including one of himself on a quad bike. It could have

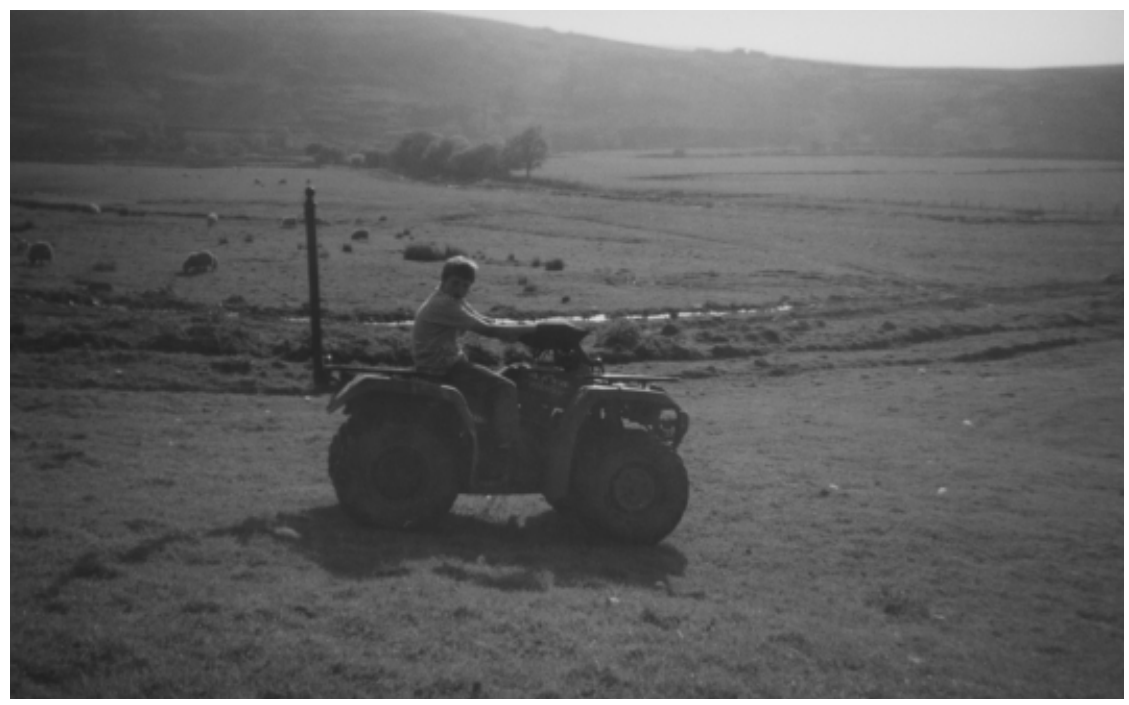


been a photograph of any boy showing off a treasured possession with no relation to working practice. But he wrote, ' $(T)$ his is when I go out on my quad to check all the sheep to see if they are all right'. In interview John had talked about riding around the large farm to perform his regular task of checking on the animals, 'I go on my quad then around the fields to check like if there is anything wrong with anything, or if anything has been killed like or died', and now he wrote the same about this photograph, simple confirmation. Without alternative data sources we risked interpretations which missed, concealed or skewed the nature of John's work, prior knowledge was important in this case.

In another, further clarification was also needed. At first sight, few pictures showed sheep farming in action, or even sheep, although in interview John had used a vivid visual metaphor, describing the huge numbers of sheep as looking like ' $a$ white blanket across the farm' when they are all gathered up together. The point was to understand why the primary work of the farm seemed missing in John's photograph. Talking with him about this he pointed to the tiny, far-off dots on the pictures. A huge flock of sheep was not the point of his photograph or his analysis of his work. The sheep are not usually gathered together, but are scattered across the huge farm. Their tiny dots on the hillsides showed us the farm's extent for the first time. It also put into context and demonstrated the significance of the earlier photograph of the quad bike. Seeing the fields and hillsides of the farm, its size, the distances John needed to cover and the size of machinery, whose use had been meticulously detailed in John's work diaries, conveyed scale. Active processes were difficult for him to capture whilst he was engaged in them, but were represented in the shots of machinery, sheds, dogs and hills. This is arguably triangulation plus something extra, the all-important topographical context, the scale of the setting that John, who at 12 years of age was already an experienced farmworker, took for granted. One reading of this example was that John had merely attempted to photograph the farm where he worked. However, this does not do justice to John as a researcher or to the capacity of Visual Sociology to convey more than just a simple visual representation. As context was added to the data by viewing the photographs alongside other data sources the significance of his representation in relation to the scale of his work became clear. Moreover, whilst John had been uniquely positioned as both photographer and subject, issues about the nature and experience of his work did not become explicit until the viewer's response had been added.

\section{Illustration or analysis?}

Although the close fit of different forms of data confirmed some accounts in a straightforward manner other more serious disjunctions required written or verbal exploration. On balance we are left with greater confirmation than challenge to earlier conventional data through the accumulation of images which closely accord with spoken and written accounts. In which case we might ask was visual research 
really needed? Have we used photography as a method for doing Visual Sociology or merely an expensive add-on to conventional qualitative sociological methods? Over time, elements of difference and the potential for analysis at a deeper level became apparent. In many cases the same account was repeated, augmented through the different media. In others our understanding was extended or changed by a further aspect of form, that of the young people's response to their own photography. In itself this is another data source.

Finally, a broader social process became evident. In the gradual accumulation of photographs from young people in different parts of the country, doing similar jobs, employed at a similar (low) level of the service sector, photographing the same tasks and processes, similar details came through the different media throughout the year, repeated, cumulative, even showing similar interiors to similar-sized modest houses, possibly indicating a similar social positioning. We see little evidence of affluence, more the mainstream, the economic middle-ground - not Middle England - but something more akin to the majority experience of fluctuating fortunes, service sector work, some financial insecurity, but most come from homes with one or more adults in work and live in small semi-detached houses on housing estates or innercity and urban terraces. In the backgrounds, potent images of surrounding environs: the terraced houses of a small Welsh former coal and steel town hit by industrial shut-down in both industries on a massive scale; razor wire atop the boundary fences of an inner-city school: another near neat well-kept estates of modern semidetached houses. As fieldworkers we knew the environs of the schools but not outlying catchment areas, nor house type nor size nor decor, nor the young people's own rooms, which some photographed to show us, often with possessions bought from their wages. The photography gave us access to broader data, perhaps beginning to take us beyond the specific cases of our research participants.

\section{Conclusion}

Our use and discussion of visual methods in sociological research so far, pose a challenge on two levels, first to sociological neglect of the meanings of visual signs and signals within society and second to the use of visual means to convey understanding to the reader who in everyday life is used to interpreting visual signals. The reader is also a viewer (Harper 1998). It is our belief that some approaches to sociology have set up and defended a false denial of our visual sense and sensibility which arguably delineates Visual Sociology as a subdiscipline. Our research advocates the role not of just photography but of Visual Sociology more generally, as an element of a broader methodology for sociological enquiry. Our argument has been that it has the capacity to produce unique datasets and to facilitate analysis which may tell us more about social phenomena than analysis of textual, verbal or observational data. However, we do not automatically wish to privilege visual over 
other forms of data and we have argued that visual methods can complement, augment, confirm and enlarge on other methods. Nevertheless, we do wish to emphasize that visual methods and visual data do have a distinctive contribution to make.

For us visual research has proved thus far most valuable in taking us beyond the taken-for-granted level and into areas which were not always clearly revealed by the young people, who could be too entangled in their own experiences of work to see the need for verbal explanation. In this context, their photographs acted as another way of 'making the familiar strange' to them and the strange familiar to us. This has particular potency when research participants take the photographs, the researcher does not know how the data will shape up, and is not therefore the final arbiter of form or content. The researcher works not only with what has been captured but also with what has not been captured. For us, the absence of people and 'action' in some of the photographs became as significant as what was captured by the photographer. By placing photography alongside other forms and sources of data and by contrasting the snapshot effect of photography with a longitudinal time-scale, we were able to include what lay beyond the frame in our analysis. The photographs worked at a number of levels, in what they depicted, in promoting questions either about what was depicted or what was absent even where this was an absence of photographs themselves and as a form of triangulation with other research methods.

Careful multi-strategy research and the creation of situated accounts, which challenge the dismissal of the photograph as only a surface representation, could add to many forms of and approaches to research. We reject the proposition that only relative or 'fictional' judgements can be made. When research participants are the sociological photographers and relationships with alternative data sources are carefully explored both of these propositions can be challenged. All the indications are that the 'phenomenon' of child employment makes more sense when explored with children within a socio-economic context, taking account of the materialist conditions which shape their lives. In this sense, we would argue that the photographs, which they produced, and the Visual Sociology which they have facilitated have resulted in accounts of rather than merely about their working lives.

ACKNOWLEDGEMENT

The research outlined here came from the Work, Labour and Economic Life in Late Childhood Project funded by the Economic and Social Research Council, as part of 'Children 5-16 Growing into the Twenty First Century', award number L129251035.

REFERENCES

Banks, M. 1998. 'Visual Anthropology: Image, Object and Interpretation', in J. Prosser, (ed.), Image-based Research: A Sourcebook for Qualitative Researchers. London: Falmer Press.

Becker, H. S. 1974. 'Photography and Sociology'. Studies in the Anthropology of Visual Communication 1:3-26. 
Becker, H. S. 1998. 'Visual Sociology, Documentary Photography, and Photojournalism: It's (Almost) All a Matter of Context', in J. Prosser (ed.), Image-based Research: A Sourcebook for Qualitative Researchers. London: Falmer.

Berger, J. 1972. Ways of Seeing. Harmondsworth: Penguin.

Chaplin, E. 1994. Sociology and Visual Representation. London: Routledge.

Cohen, P. 1997. Rethinking the Youth Question. Basingstoke: Macmillan.

Collier Jr, J. 1967. Visual Anthropology: Photographs as a Research Method. New York: Holt, Reinhart, Winston.

Davis, M. 1993. 'The Dead West: Ecocide in Marlboro Country'. New Left Review 200:49-73.

Feldman, M. 1995. Analysing Qualitative Research. London: Sage.

Finch, J.1986. Research and Policy: The Use of Qualitative Methods in Social and Educational Research. London: Falmer Press.

Ganzel, B. 1984. Dustbowl Descent. Lincoln: University of Nebraska Press.

Harper, D. 1982. Good Company. Chicago: University of Chicago Press.

Harper, D. 1998. 'An Argument for Visual Sociology, in J. Prosser (ed.), Image-based Research: A Sourcebook for Qualitative Researchers. London: Falmer.

Hebdige, D. 1988 Hiding in the Light. London: Routledge.

Hubbard, J.1991. Shooting Back: A Photographic View of Life by Homeless Children. San Francisco: Chronicle Books.

Klett, M., Manchester, E. et al.1984. Second View: The Rephotographic Survey Project. Albuquerque: University of New Mexico Press.

Misrach, R. 1992. Violent Legacies: Three Cantos. New York: Aperture Foundation.

Mizen, P., Bolton, A., and Pole, C. 1999. 'School Age Workers: The Paid Employment of Children in Britain'. Work, Employment and Society 13:423-38.

Mizen, P. and Pole, C. 1997. Work, Labour and Economic Life in Late Childhood. ESRC Children 5-16 Programme Pack. Swindon: Economic and Social Research Council.

Payne, G. 1993. 'The Community Revisited: Some Reflections on the Community Study as a Method'. Unpublished conference paper, British Sociological Association Annual Conference, University of Essex.

Plummer, K. 1983. Documents of life. London: Allen and Unwin.

Pole, C., Mizen, P., and Bolton, A. 1999. 'Realizing Children's Agency in Research: Partners and Participants?' International Journal of Social Research Methodology 2:39-54.

Prosser, J. and Schwartz, D. 1998. 'Photographs within the Sociological Research Process', in J. Prosser (ed.), Image-based Research: A Sourcebook for Qualitative Researchers. London: Falmer.

Rieger, J.H. 1982. 'Rural Nonfarm Residence in the Midwest'. Rural Sociologist 2:215-32.

Rieger, J. H. 1996.' 'Photographing social change'. Visual Sociology11:5-49.

Worth, S. 1980. 'Margaret Mead and the Shift from Visual Anthropology to the Anthropology of Visual Communication'. Studies in Visual Communication 6:15-22.

Worth, S. and Adair, J.1972. Through Navajo Eyes: An Exploration in Film Communication and Anthropology, Bloomington: Indiana University Press.

Biographical note: ANGELA BOLTON is senior policy officer at Barnardos. CHRISTOPHER POLE is Senior Lecturer in Sociology at the University of Leicester. PHILLIP MIZEN is Lecturer in Sociology at the University of Warwick.

Address: Christopher Pole, Department of Sociology, University of Leicester, University Road, Leicester, LE1 7 RH. 